\title{
SCIDiC
}

\author{
International Journal of Dentistry and Oral Science (IJDOS) \\ ISSN: $2377-8075$
}

\section{Assessing the Reason for Retreatment in Molar Teeth - A Retrospective Study}

Research Article

Keerthika $\mathrm{R}^{1}$, Surendar Sugumaran ${ }^{2 *}$, Sowmya $\mathrm{K}^{2}$

${ }^{1}$ Saveetha Dental College and Hospitals, Saveetha Institute of Medical and Technical Sciences, Chennai, Tamil Nadu, India.

${ }^{2}$ Senior Lecturer, Saveetha Dental College and Hospitals, Saveetha Institute of Medical and Technical Sciences, Chennai, Tamil Nadu, India.

\section{Abstract}

Aim: The aim of this study was to assess the reason for retreatment in endodontically treated molar teeth.

Materials and Methods: A retrospective cross sectional study was conducted from the period of June 2019 to April 2020. Patient records from the electronic database were reviewed and only the patients who underwent retreatment of endodontically treated teeth were assessed. In this study a total of 95 molar teeth which were retreated was included and age, gender, type of teeth / position of teeth and reason for retreatment was assessed. The association between the factors were assessed using chi square test. The statistical analysis between the groups was carried out in SPSS software.

Result: Results showed that of the 95 molar teeth. The reason for retreatment was predominated by incomplete obturation $(n=44)$, which was followed by lesion $(n=21)$, symptomatic treatment $(n=18)$ and missed canal $(n=10)$. The chi square test for association of the teeth type to the reason of retreatment with the $\mathrm{p}$ value $=0.160(>0.05)$, which implies that there is no significant association between the type of teeth and the reason of retreatment.

Conclusion: It was concluded that the most common reason for retreatment was incomplete obturation,Mandibular molars were the most commonly retreated teeth than the maxillary molars.

Keywords: Endodontically Treated Teeth; Incomplete Obturation; Missed Canal; Molar; Retreatment; Retrospective Study.

\section{Introduction}

Endodontic treatment aims at removing the infected/necrotic tissues from the root canal system and maintaining the function of the oral environment [1]. Though endodontic treatment shows nearly $90 \%$ success rate [2], non surgical endodontic treatment fails when adequate standards are not maintained. The two main treatment protocols done usually after the failure of endodontic treatments are retreatment and surgical endodontics [3]. Even if this fails, extraction remains the last mode of treatment. The outcome of the endodontically treated teeth has to be evaluated both clinically [4] and radiographically [5-7]. The most common factors attributed to endodontic failure are persistent bacteria [8], inadequate filling of the canal, overextension of root canal filling materials, improper coronal seal [9], untreated canal, iatrogenic procedural errors (poor access designs, complications of instrumentation) [10], unresolved periapical pathology [9, 10]. The other attributable etiological factors could be the extra radicular infection, foreign body reaction and true cysts [11].
The management of teeth which were previously endodontically treated is always technically challenging and time consuming procedure due to the presence of extensive restorations like post and cores, crowns and bridges,etc. The principle difference between the primary endodontic disease and the retreatment/posttreatment disease during the nonsurgical management is need to regain the access to the apical region of the teeth which was already endodontically treated [12].

Diagnosis of post treatment disease has been done usually with the help of radiographs, CBCT, comparative testing using objective information of both the pulpal and periradicular tissues and by pulp vitality test. Though the vitality test of endodontically treated is of less importance, thermal test was preferred in situation demanding them [12].

Various factors also determine the success of endodontic treatment which include initial cause for infection [13,14] and inflam-

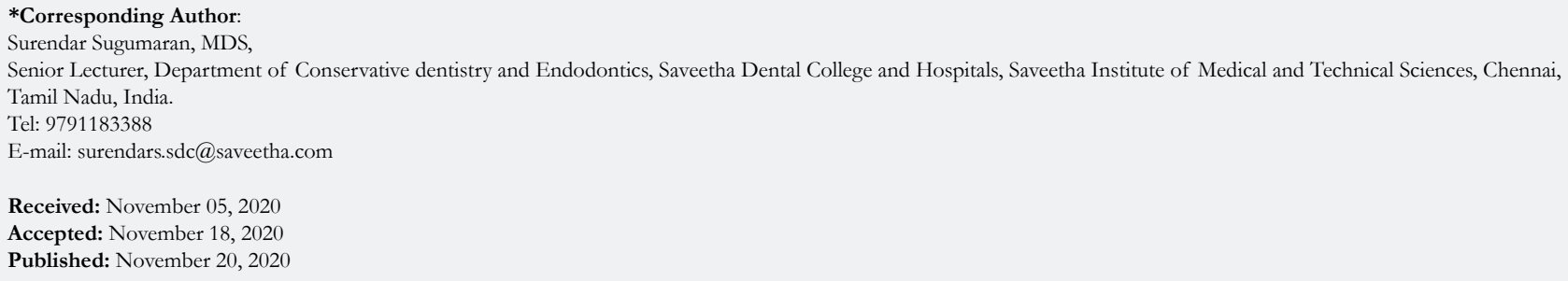

Copyright: Surendar Sugumaran ${ }^{\circ} 2020$. This is an open-access article distributed under the terms of the Creative Commons Attribution License, which permits unrestricted use, distribution and reproduction in any medium, provided the original author and source are credited. 
mation, environment of the affected teeth [15], diagnostic aids used [16, 17], anatomical consideration [18], instrumentation protocol, type of irrigants used [19, 20] and its activation protocol [21], sealers used [22, 23], obturating materials, coronal seal [24], permanent restorations like veneers [25], periapical pathosis and intra oral environment [26]. Several studies have been published to analyse the reason for extraction of the endodontically treated teeth [27-31]. Among all the reasons for extraction, the second most important cause being endodontic failure which accounts for $20 \%$ approximately [32]. Being an important topic of research with future research should be focused not only on the prevalent reason for extraction but also should be focused on the reasons causing failure.

The aim of the present retrospective study was to analyse the various reasons for retreatment in endodontically treated molar teeth like incomplete obturation, periapical pathology, missed canal, symptomatic treatment. It also focuses on the association between the reasons of retreatment with personal characteristics of the patient like age, gender and teeth position.

\section{Materials and Method}

\section{Study design and setting}

This was a retrospective study done in Chennai during the period of July 2019-April 2020. It was done from one particular university set up with a non probability sampling method.

\section{Ethical Approval}

Ethical approval was obtained from the institutional Ethics Committee. Ethical Approval Number SDC/SIHEC/2020/DIASDATA/0619-0320.

\section{Data collection}

Data of patients who underwent retreatment of endodontically teeth from a period of July 2019 - April 2020 was collected from the electronic database.

\section{Inclusion criteria}

Case sheets of all cases which underwent retreatment $(n=308)$ were analysed and reviewed, of which only the molar teeth were included. Patients from the age group of 18- 60 years were only included.

\section{Exclusion criteria}

The teeth without mentioning the reason for retreatment (i.e) incomplete data were excluded. Inorder to avoid errors radiographic cross verification was done and two reviewers were included. The validity of the samples were checked which included that all teeth were endodontically treated after failure, reason for retreatment could be assessed, proper diagnostic methods available to assess the failure.

Total of 95 cases were evaluated and only one reason for retreatment was considered and evaluated. The reasons for retreatment considered were incomplete obturation, lesion, missed canal, symptomatic treatment and others. The quality of root canal fillings were assessed using radiographs.

\section{Statistical analysis}

The acquired data were recorded in Microsoft excel and later exported to IBM SPSS software (version 20.0 Chicago,USA) for statistical analysis. Chi square test was then employed with the level of significance set at $\mathrm{P}<0.05$. The statistical analysis between age, gender, teeth number, reason for retreatment were analysed using SPSS software. The outcome was represented in the form of tables and bar charts.

\section{Results and Discussion}

A total of 95 teeth was included in the study which corresponds to the patients of age group 18- 60 years, of which age group of 18-30 years had higher incidence of retreatment $(n=43)$ followed by $31-40$ years $(n=21), 41-50$ years $(n=20)$ and $51-60$ years $(n=11)$. (Figure I)

Major proportion of the study population was constituted by males $(n=54)$ than the females $(n=41)$.(Figure II)

Among the molar teeth included in the study, Mandibular molars $(n=62)$ were higher in number than the maxillary molars $(n=33)$. (Figure III)

The various reasons for retreatment were categorised as incomplete obturation, lesion, symptomatic treatment, missed canals and others of which the incomplete obturation $(n=44)$ was the most common reason followed by lesion $(n=21)$, symptomatic treatment $(\mathrm{n}=18)$ missed canal $(\mathrm{n}=10)$ and others. (Figure IV)

Among the mandibular molars $(n=62)$, the distribution of reason for retreatment was incomplete obturation $(n=33)$, lesion $(n=13)$, symptomatic treatment $(\mathrm{n}=10)$ and missed canal $(\mathrm{n}=8)$. Among the maxillary molars $(n=33)$ the distribution was seen as incomplete obturation $(n=11)$, lesion $(n=8)$, symptomatic treatment $(\mathrm{n}=8)$, missed canal $(\mathrm{n}=4)$ and others $(\mathrm{n}=2) .($ Figure $\mathrm{V})$

The chi square test showed that $\mathrm{p}$ value of the study was $\mathrm{p}=$ 0.16 which is greater than the considered level of significance $(p<0.05)$. 'Hence it can be inferred that there was no significant relation between the type of teeth and the reason for retreatment. (Table I)

The data for this retrospective study was based on residents of Chennai. Since all data available was included without a sorting process, no bias was expected in selection of patients.

In this present study, the rate of failure/rate of retreatment was higher in younger patients than that of older age groups. It was in compliance with the study by Ricucci et al., [33], which showed that rate of failure decreases with increase in age .Contradicting to these findings were found by Swartz et al [34], which concluded that there was no association between the age and the failure of endodontic treatment. But the distribution of age group in this present study was not homogeneous hence it cannot be concluded as an attributable risk factor. 
Figure 1. Bar chart showing the frequency distribution of age group of the study population and number of endodontic retreatment with the $\mathrm{X}$ axis denoting distribution of age groups and $\mathrm{Y}$ axis denoting number of endodontic retreatment Graph reveals that between 18-30 yrs showed more case distribution followed by 31-40 yrs, $41-50$ yrs, 51-60 yrs respectively.

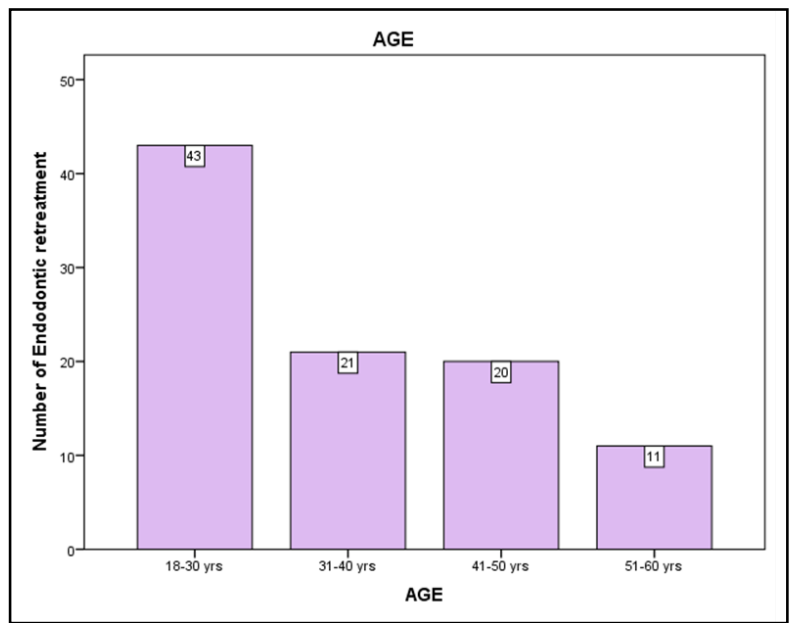

Figure 2. Bar chart showing the frequency distribution of gender of the study population and number of endodontic retreatment with $\mathrm{X}$ axis showing distribution of gender and $\mathrm{Y}$ axis shows number of endodontic retreatment. Graph reveals that among the study population male patients $(n=54)$ were higher in number than the female patients $(n=41)$.

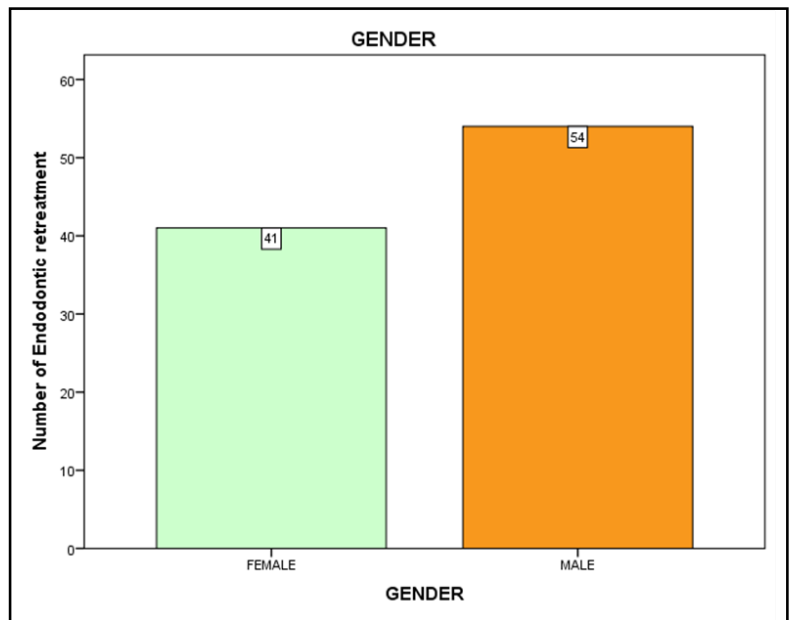

Figure 3. Bar chart showing the frequency distribution of molar teeth among the study population and number of endodontic retreatment with $\mathrm{X}$ axis denotes teeth number (maxillary and mandibular molars)and $\mathrm{Y}$ axis denotes the number of endodontic retreatment. Graph reveals that among the study population mandibular molars $(\mathrm{n}=33)$ showed maximum number of retreatment cases than the maxillary molars $(n=62)$.

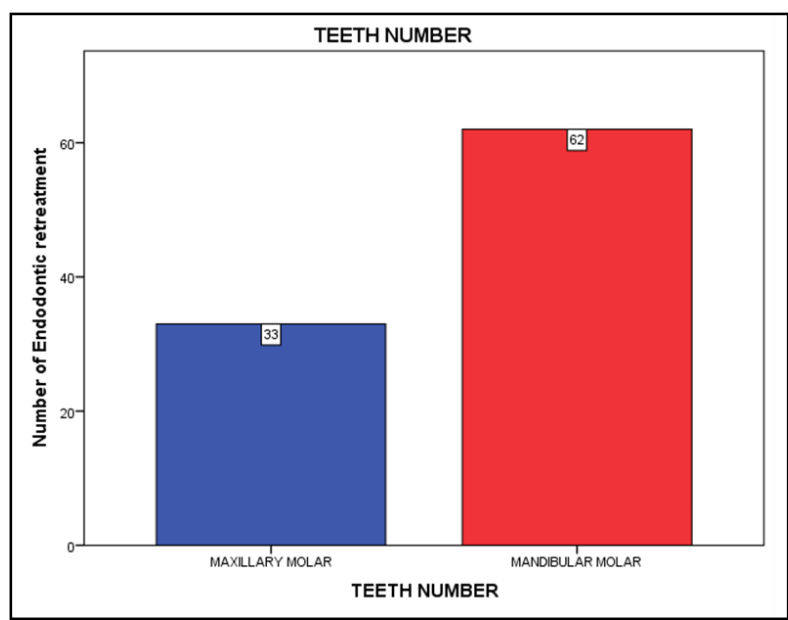


Figure 4. Bar chart showing the frequency distribution of reason for retreatment and number of endodontic retreatment with $\mathrm{X}$ axis denotes the reason for retreatment and $\mathrm{Y}$ axis show number of endodontic retreatment.Graph reveals that among the reasons for retreatment the most predominant was incomplete obturation followed by lesion,symptomatic treatment ,missed canal and others respectively.

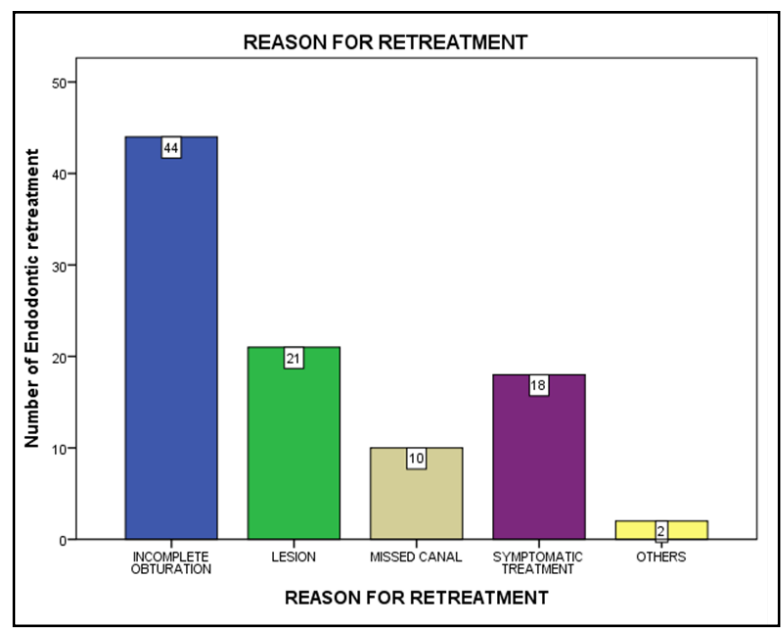

Figure 5. Bar chart showing the distribution of reasons for retreatment among the molar teeth with $\mathrm{X}$ axis representing the type of teeth(maxillary /mandibular molars) and Y axis representing the number of endodontic retreatment .Graph reveals that among the maxillary molars $(n=33)$, the reason for retreatment was predominated by incomplete obturation(11) followed by lesion(8), symptomatic treatment (8), missed canal (4)and others (2) and among the mandibular molars (62), incomplete obturation(33) followed by lesion(13),symptomatic treatment (10), missed canal (8). Pearson's chi square value $: 6.573$, df $: 4, \mathrm{p}$ value $: 0.16(>0.05)$ hence statistically not significant, proving there was no significant association between the teeth type and the reason for retreatment.

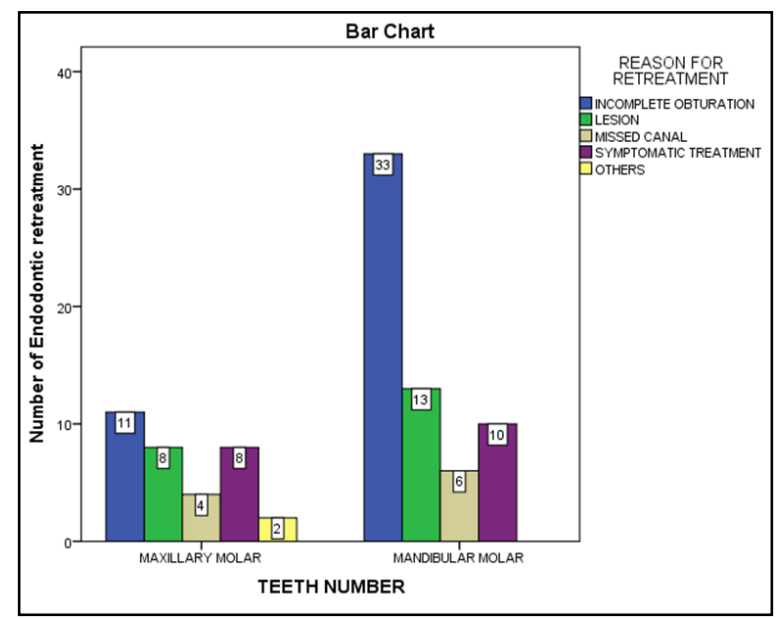

Table I. Association of the teeth type to the reason of retreatment with the palue $=0.160(>0.05)$, which implies that there is no significant association between the type of teeth and the reason of retreatment with the chi square test.

\begin{tabular}{|c|c|c|c|}
\hline & Value & df & Asymp. Sig (2-sided) \\
\hline Pearson Chi-square & $6.573^{\mathrm{a}}$ & 4 & 0.16 \\
\hline Lokelihood Ratio & 7.116 & 4 & 0.13 \\
\hline Linear by Linear & 4.548 & 1 & 0.033 \\
\hline Association & & & \\
\hline N of Valid Cases & 95 & & \\
\hline
\end{tabular}

Among the gender distribution, Male had a higher rate of retreatment than females, which was in acceptance with the study by Zadik et al., [31] but a study by Touere et al., [32] was contradicting saying that there was no significant association between the gender and the success of root canal treatment. The type of the teeth affected by endodontic failure and which undergoes retreatment was in accordance with Ricucci et al., [33] but was contradicted by Song et al., [8] stating that maxillary teeth had a higher rate of retreatment than the mandibular teeth. The most attributing reason for retreatment in mandibular molars could be the higher incidence of curvature and the presence of isthmus.These anatomical considerations make it difficult to establish a completely disinfected root canals. To overcome this situation, knowledge on the anatomic complexities and the sound knowledge on the diagnostic techniques like CBCT and careful examination of the preoperative radiographs were highly essential. 
In this study, incomplete obturation was the predominant reason for retreatment which is in accordance with the study by Rucci et al [33], Zadik et al., [31] which showed the endodontic failure as most common reason for failure of treatment. The contradicting literature like vire et al [27], Chen et al [30], Touere et al., [32] has stated prosthetic failure, restorative failure, periodontal causes as the reason for retreatment. Untreated or missed out canals could not be considered as an uncommon scenario during endodontic treatment. A prospective study by Hoen and Pink has shown incidence of missed canal to be $42 \%$ in endodontically failed teeth [5].

Persistence of the periapical infection also contribute to the failure of endodontic treatment, which could be influenced by various factors like organism causing infection, time lapse between the initial phase and final phase of treatment, endodontic protocol and instrument used, irrigant used for disinfection, obturating materials used and also the coronal seal used [35]. A study by Yamaguchi showed various causes for treatment failure of root canal treated teeth as open apices, missed canal, insufficient enlargement of the root canal, perforation, fin isthmus, transportation, residual caries, root fracture, inaccessible root apex and separate instruments [36].

The limitations of this study was that only a small group of population was assessed in a closed environment and the reason for failure of endodontic treatment was not assessed and the interrelationships between the cause and failure was not assessed. Thus in future more focus on the above mentioned factors has to be considered and the study has to be done in a larger population.

\section{Conclusion}

Within the limitations of this study it can be concluded that the most common reason for retreatment of endodontically treated teeth was incomplete obturation and mandibular molar were the commonly retreated teeth than the maxillary teeth.There was no statistically significant association between the teeth type and reason for retreatment in endodontically treated teeth. In this study various reasons for retreatment of molars were assessed.

\section{Clinical Significance}

Our present study reveals that incomplete obturation was the predominant reason for retreatment, it could be avoided by using proper protocol, using the advanced diagnostic aids like CBCT, better endodontic sealers which are appropriate for the particular situation and also evaluating the anatomic complexities. Iatrogenic causes like perforation, transportation, stripping, overinstrumentation and under instrumentation, broken instruments should also be minimised or avoided for better clinical outcome.

\section{Acknowledgement}

With sincere gratitude, we acknowledge the staff members of the Department of Conservative Dentistry and Endodontics and study participants for the extended support towards the completion of the research.

\section{Author Contribution}

Keerthika .R, contributed in concept, acquisition of data analysis, interpretation of data and also drafting the article and revising it critically for important intellectual content and manuscript preparation.

Surendar. S and Sowmya K, contributed in study design, correction, alignment, preparation of manuscript, supervision and formatting with final approval of the submitted version of the manuscript.

\section{References}

[1]. Olcay K, Ataoglu H, Belli S. Evaluation of Related Factors in the Failure of Endodontically Treated Teeth: A Cross-sectional Study. J Endod. 2018 Jan;44(1):38-45.Pubmed PMID: 29246376.

[2]. Lewis RD, Block RM. Management of endodontic failures. Oral Surgery, Oral Medicine, Oral Pathology. 1988 Dec 1;66(6):711-21.

[3]. Salehrabi R, Rotstein I. Endodontic treatment outcomes in a large patient population in the USA: an epidemiological study. J Endod. 2004 Dec;30(12):846-50.Pubmed PMID: 15564861.

[4]. Ashley M, Harris I. The assessment of the endodontically treated tooth. Dental update. 2001 Jun 2;28(5):247-52.

[5]. Tabassum S, Khan FR. Failure of endodontic treatment: The usual suspects. Eur J Dent. 2016 Jan-Mar;10(1):144-147.Pubmed PMID: 27011754.

[6]. Ray HA, Trope M. Periapical status of endodontically treated teeth in relation to the technical quality of the root filling and the coronal restoration. Int Endod J. 1995 Jan;28(1):12-18.Pubmes PMID: 7642323.

[7]. Eckerbom M, Magnusson T. Evaluation of technical quality of endodontic treatment--reliability of intraoral radiographs. Endod Dent Traumatol. 1997 Dec;13(6):259-64.Pubmed PMID: 9558506.

[8]. Song M, Kim HC, Lee W, Kim E. Analysis of the cause of failure in nonsurgical endodontic treatment by microscopic inspection during endodontic microsurgery. J Endod. 2011 Nov;37(11):1516-9.Pubmed PMID: 22000454.

[9]. Segura-Egea JJ, Jiménez-Pinzón A, Poyato-Ferrera M, Velasco-Ortega E, Ríos-Santos JV. Periapical status and quality of root fillings and coronal restorations in an adult Spanish population. Int Endod J. 2004 Aug;37(8):52530.Pubmed PMID: 15230905.

[10]. Sjögren U, Figdor D, Persson S, Sundqvist G. Influence of infection at the time of root filling on the outcome of endodontic treatment of teeth with apical periodontitis. Int Endod J. 1997 Sep;30(5):297-306. Pubmed PMID: 9477818.

[11]. Essential Endodontology - Prevention And Treatment Of Apical Periodontitis. Australian Endodontic Journal 1998; 24: 138-139.

[12]. Hargreaves KM, Berman LH. Cohen's pathways of the pulp expert consult. Elsevier Health Sciences; 2015 Oct 2.

[13]. Teja KV, Ramesh S, Priya V. Regulation of matrix metalloproteinase-3 gene expression in inflammation: A molecular study.J Conserv Dent. 2018 Nov;21(6):592.

[14]. Jose J, Subbaiyan H. Different Treatment Modalities followed by Dental Practitioners for Ellis Class 2 Fracture-A Questionnaire-based Survey. Open Dent. J. 2020 Feb 18;14(1):59-65.

[15]. Rajakeerthi R, Ms N. Natural Product as the Storage medium for an avulsed tooth-A Systematic Review. Cumhur. Dent. J. 2019;22(2):249-56.

[16]. Ramanathan S, Solete P. Cone-beam Computed Tomography Evaluation of Root Canal Preparation using Various Rotary Instruments: An in vitro Study. J. Contemp. Dent. Pract. 2015 Nov 1;16(11):869-72.

[17]. Janani K, Palanivelu A, Sandhya R. Diagnostic accuracy of dental pulse oximeter with customized sensor holder, thermal test and electric pulp test for the evaluation of pulp vitality: an in vivo study. Braz. Dent. Sci. 2020 Jan 31;23(1):8.

[18]. Kumar D, Antony S. Calcified Canal and Negotiation-A Review. Res J Pharm Technol. 2018;11(8):3727-30

[19]. Siddique R, Jayalakshmi S. Assessment of Precipitate Formation on Interaction of Chlorhexidine with Sodium Hypochlorite, Neem, Aloevera and Garlic: An in vitro Study. . Indian J Public Health Res Dev. 2019 Nov $1 ; 10(11): 3648-3652$.

[20]. Noor, S. Chlorhexidine: Its properties and effects. Res J Pharm Technol. 2016;9(10):1755-1760.

[21]. Ramamoorthi S, Nivedhitha MS, Divyanand MJ. Comparative evaluation of postoperative pain after using endodontic needle and EndoActivator dur- 
ing root canal irrigation: A randomised controlled trial. Aust Endod J. 2015 Aug;41(2):78-87.Pubmed PMID: 25195661.

[22]. Rajendran R, Kunjusankaran RN, Sandhya R, Anilkumar A, Santhosh R, Patil SR. Comparative Evaluation of Remineralizing Potential of a Paste Containing Bioactive Glass and a Topical Cream Containing Casein Phosphopeptide-Amorphous Calcium Phosphate: An in Vitro Study. Pesqui. Bras. Odontopediatria Clin. 2019;19.

[23]. Manohar MP, Sharma S. A survey of the knowledge, attitude, and awareness about the principal choice of intracanal medicaments among the general dental practitioners and nonendodontic specialists. Indian J Dent Res. 2018 Nov-Dec;29(6):716-720.Pubmed PMID: 30588997.

[24]. Hussainy SN, Nasim I, Thomas T, Ranjan M. Clinical performance of resinmodified glass ionomer cement, flowable composite, and polyacid-modified resin composite in noncarious cervical lesions: One-year follow-up. J Conserv Dent. 2018 Sep-Oct;21(5):510-515.Pubmed PMID: 30294112.

[25]. Ravinthar K. Recent advancements in laminates and veneers in dentistry. Res J Pharm Technol. 2018;11(2):785-7.

[26]. Nandakumar M, Nasim I. Comparative evaluation of grape seed and cranberry extracts in preventing enamel erosion: An optical emission spectrometric analysis. J Conserv Dent. 2018 Sep-Oct;21(5):516-520.Pubmed PMID: 30294113.

[27]. Vire DE. Failure of endodontically treated teeth: classification and evaluation. J Endod. 1991 Jul;17(7):338-42.Pubmed PMID: 1779219.

[28]. Tzimpoulas NE, Alisafis MG, Tzanetakis GN, Kontakiotis EG. A prospective study of the extraction and retention incidence of endodontically treated teeth with uncertain prognosis after endodontic referral. J Endod. 2012 Oct;38(10):1326-9.Pubmed PMID: 22980171.
[29]. Fuss Z, Lustig J, Tamse A. Prevalence of vertical root fractures in extracted endodontically treated teeth. Int Endod J. 1999 Aug;32(4):283-6.Pubmed PMID: 10551119.

[30]. Chen SC, Chueh LH, Hsiao CK, Wu HP, Chiang CP. First untoward events and reasons for tooth extraction after nonsurgical endodontic treatment in Taiwan. J Endod. 2008 Jun;34(6):671-4.Pubmed PMID: 18498886.

[31]. Zadik Y, Sandler V, Bechor R, Salehrabi R. Analysis of factors related to extraction of endodontically treated teeth. Oral Surg Oral Med Oral Pathol Oral Radiol Endod. 2008 Nov 1;106(5):e31-5.

[32]. Touré B, Faye B, Kane AW, Lo CM, Niang B, Boucher Y. Analysis of reasons for extraction of endodontically treated teeth: a prospective study. J Endod. 2011 Nov;37(11):1512-5.Pubmed PMID: 22000453.

[33]. Ricucci D, Russo J, Rutberg M, Burleson JA, Spångberg LS. A prospective cohort study of endodontic treatments of 1,369 root canals: results after 5 years. Oral Surg Oral Med Oral Pathol Oral Radiol Endod. 2011 Dec;112(6):825-42.Pubmed PMID: 22099859.

[34]. Swartz DB, Skidmore AE, Griffin JA. Twenty years of endodontic success and failure. J Endod. 1983 May 1;9(5):198-202.

[35]. Curtis DM, VanderWeele RA, Ray JJ, Wealleans JA. Clinician-centered Outcomes Assessment of Retreatment and Endodontic Microsurgery Using Cone-beam Computed Tomographic Volumetric Analysis. J Endod. 2018 Aug;44(8):1251-1256.Pubmed PMID: 29970237.

[36]. Yamaguchi M, Noiri Y, Itoh Y, Komichi S, Yagi K, Uemura R, et al. Factors that cause endodontic failures in general practices in Japan. BMC Oral Health. 2018 Apr 27;18(1):70.Pubmed PMID: 29703201 